6 Redhead DN. Inferior vena caval filters. $\mathcal{Y}$ Intervent Radiol 1993; 8: 121-6.

7 Berland LL, Maddison FE, Bernhard VM. Radiological follow up of vena cava filter devices. $A \mathcal{F}$ 1980;134; 1047-52.

8 Greenfield LJ, Savin MA. Comparison of titanium and stainless steel Greenfield vena cava filters. Surgery 1989 ; 106: 820-8.

9 Dorsey R, Bayazid S, Diethrich EB. Migrated KimrayGreenfield filter lodged in the right ventricle: surgical Greenfield filter lodged in the right ventricle: surgical Surg 1993; 106: 1230-1.

10 Rodriguez LF, Saltiel FS. Long term follow-up of ectopic intra-cardiac Greenfield filter. Chest 1993; 104: 611-2.

11 Rao KM, Simons AJ, Hare CL, Smulyan H. Migration of a Kimray-Greenfield filter into the pulmonary artery: localisation by trans-oesophageal echocardiography. $A m$ Heart $\mathcal{F}$ 1993; 4: 565-8.

12 Gomez GA, Culter BS, Wheeler HB. Trans/venous interruption of the inferior vena cava. Surgery 1983; 93: 612-9.
13 Messmer JM, Greenfield LJ. Greenfield caval filters: long term radiographic follow up study. Radiology 1985; 156: 613-8.

14 Wingerd $M$, Bernhard VM, Maddison F, Towne JB. Comparison of caval filters in the management of venous thrombo-embolism. Arch Surg 1978; 1134: 1264-71.

15 Berland LL, Maddison F, Bernhard VM. Radiological follow up of vena cava filter devices. AfR 1980; 134: 1047-52.

16 Kurgan A, Nunnelee JD, Auer AI. Penetration of the wall of an abdominal aortic aneurysm by a Greenfield filter prong: a an abdominal aortic aneurysm by a Greenfield filter

17 Miller CL, Wechsler RJ. CT evaluation of Kimray-

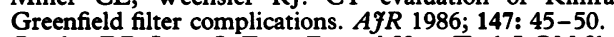

18 Crochet DP, Stora O, Ferry D, et al. Vena Tech LGM filter long term results of a prospective study. Radiology 1993; 188: $857-60$.

\title{
Acute pancreatitis due to zinc phosphide ingestion
}

\author{
PSA Sarma, Jyotee Narula
}

\begin{abstract}
Summary
The case of a young woman is described who suffered from acute pancreatitis related to the ingestion of zinc phosphide. This unusual complication was successfully managed with conservative treatment.
\end{abstract}

Keywords: pancreatitis, zinc phosphide

Zinc phosphide is a commonly used rodenticide in India. When exposed to moisture, or gastric juice hydrochloride, it liberates highly lethal phosphine gas $\left(\mathrm{PH}_{3}\right)$, producing various metabolic and non-metabolic toxic effects. ${ }^{1-3}$ Mortality due to $\mathrm{PH}_{3}$ is very high $(37-100 \%)$. The clinical and pathological features are shown in box 1 . The poisoning may also result in hypoglycaemia, ${ }^{2}$ but not to date, acute pancreatitis. We report a case of acute pancreatitis due to zinc phosphide ingestion that was successfully treated.

\section{Case report}

A 21-year-old woman was hospitalised six hours after ingestion of zinc phosphide. On examination, she appeared drowsy and her vital signs were normal. Twelve hours after admission, she was found to be stuporose but irritable, febrile $\left(37.4^{\circ} \mathrm{C}\right)$, jaundiced and hypotensive. Signs of metabolic acidosis and peripheral circulatory failure were present. Epigastric tenderness and generalised abdominal distension with absent intestinal peristaltic sounds were noted. Laboratory studies showed haemoglobin $110 \mathrm{~g} / \mathrm{l}$, hyperglycaemia (glucose $161 \mathrm{mmol} / \mathrm{l}$ ), raised blood urea nitrogen $7.1 \mathrm{mmol} / \mathrm{l}$, creatinine $124 \mu \mathrm{mol} /$ 1, hyperbilirubinaemia (bilirubin $72 \mu \mathrm{mol} / \mathrm{l}$ ), raised hepatic enzymes (aspartate aminotransferase $706 \mathrm{U} / 1$, alanine aminotransferase
$617 \mathrm{U} / 1)$, hyperamylasaemia (2132 U/1), hyperkalaemia (6.2 mmol/1), hypoalbuminaemia (32 $\mathrm{g} / \mathrm{l})$, hypocalcaemia (1.9 mmol/1), glycosuria and ketonuria. An abdominal X-ray showed generalised ileus with air-fluid levels. Ultrasound demonstrated an oedamatous, enlarged pancreas. She was treated conservatively with intravenous fluids, fasting, nasogastric suction, antibiotics, $\mathrm{H}_{2}$-blockers, analgesics, and crystalline insulin injections guided by blood glucose estimations.

Over the next four days, she became normotensive; cyanosis and jaundice disappeared; tenderness and abdominal distension decreased. Blood glucose and potassium were reduced to $60 \mathrm{mmol} / 1$ and $40 \mathrm{mmol} / 1$, respectively, glycosuria and ketonuria disappeared but urinary amylase levels rose to $11873 \mathrm{U} / 1$. Repeat ultrasound performed on the seventh hospital day showed marked decrease in pancreatic oedema. After 17 days serum albumin rose to $38 \mathrm{~g} / \mathrm{l}$, and calcium to $2.13 \mathrm{mmol} / \mathrm{l}$. Blood urea nitrogen, creatinine, bilirubin, aspartate aminotransferase, and alanine aminotransferase were reduced to $4.26 \mathrm{mmol} / \mathrm{l}$, $88.4 \mu \mathrm{mol} / \mathrm{l}, \quad 18.1 \mu \mathrm{mol} / \mathrm{l}, \quad 50 \mathrm{U} / \mathrm{l}, \quad 50 \mathrm{U} / \mathrm{l}$, respectively and normalised after an additional week with the exception of a slight rise in amylase to $66 \mathrm{U} / 1$, and urinary amylase to $575 \mathrm{U} / 1$.

The patient is well two months after discharge. Ultrasound and computed tomography showed a normal pancreas.

\section{Discussion}

$\mathrm{PH}_{3}$ causes non-competitive inhibition of cytochrome oxidase, and insect catalase, and a change in the dichroic spectrum of haemoglobin, suggesting a valency change in haem accompanied by conformational changes in the prosthetic group. ${ }^{1,4}$ The exact pathogenesis of $\mathrm{PH}_{3}$-induced organ toxicity is not well under- 


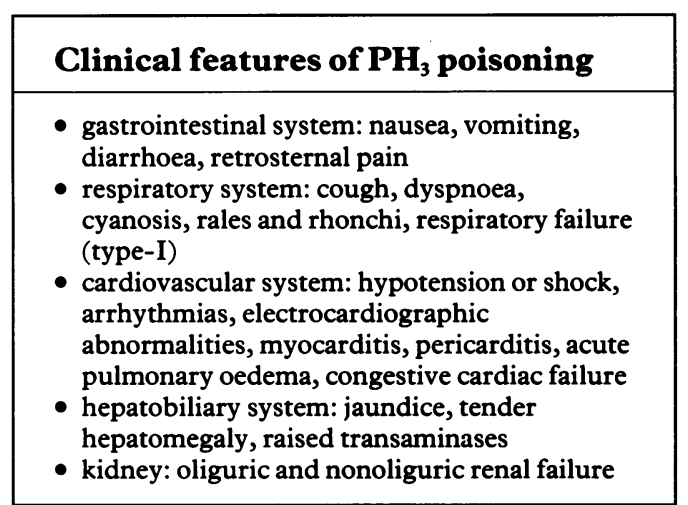

Box 1

stood, but appears to be hypoxic and, if recovery occurs, it is complete, without residual effects. ${ }^{1}$

In their review article, Steinberg and Tenner ${ }^{5}$ described acute pancreatitis as a disorder with numerous causes which may result in anything from a mild disease to multiorgan failure and sepsis; it has an obscure pathogenesis, few effective remedies, and an often unpredictable outcome. Toxin-induced acute pancreatitis is uncommon. Only five toxins were mentioned as toxicological causes of acute pancreatitis, with ethyl alcohol the most common, accounting for $35 \%$ of cases. ${ }^{5} \mathrm{~A}$ report published in $1980^{6}$ implicated pyriminil (Vacor), a nitrosourea-derived rodenticide in its aetiology. In a recent report, Gasser et al

1 Chugh SN. Aluminium phosphide poisoning: present status 2 and management. F Assoc Physicians India 1992; 40: 401-5. Patil RK, Bansal SK, Kashyap S, Sharma AK, Sharma B. Physicians India 1990; 38: 306-7.

3 Sangle SA, Thomas A, Verma S, Wadia RS. Zinc phosphide poisoning. I Assoc Physicians India 1987; 35: 591-4.

4 Kashi KP, Chefurka W. The effect of phosphine on absorbtion and circular dichroic spectra of cytochrome $C$ and cytochrome C oxidase. Pest Biochem Physiol 1976: 6: 350-62.
Toxicological causes of acute pancreatitis

- ethyl alcohol

- methyl alcohol

- scorpion venom

- organo-phosphorus insecticides

- pyriminil (Vacor)

- pentavalent antimonial agents

- zinc phosphide

Box 2

\section{Learning points}

- toxin-induced acute pancreatitis is rare

- $\mathrm{PH}_{3}$-induced organ toxicity appears to be hypoxic and if recovery occurs, it is complete without residual effects

- zinc phosphide may be included in the expanding list of toxicological causes of acute pancreatitis

Box 3

described pancreatitis induced by pentavalent antimonial agents during treatment of leishmaniasis (box 2).

Zinc phosphide should be included in the expanding list of identifiable, remediable toxic causes of acute pancreatitis.

5 Steinberg W, Tenner S. Acute pancreatitis. $N$ Engl $\mathcal{Y}$ Med 1994; 330: 1198-210.

6 Karan JH, Lawitt PA, Young CW, et al. Insulinopenic diabetes after rodenticide (Vacor) ingestion: a unique mode of acquired diabetes in man. Diabetes 1980; 29: 971-8.

7 Gasser RA, Magill AJ, Oster CN, Franks ED, Grogel $M$ Berman JD. Pancreatitis induced by pentavalent antimonia agents during treatment of leishmaniasis. Clin Infect Dis 1984; 18: 83-90. 